\title{
Transcriptome signatures of class I and III stress response deregulation in Lactobacillus plantarum reveal pleiotropic adaptation
}

\author{
Hermien Van Bokhorst-van de Veen ${ }^{1,2,3,7}$, Roger S Bongers ${ }^{1,2,8}$, Michiel Wels ${ }^{1,2,4}$, Peter A Bron ${ }^{1,2,5}$
} and Michiel Kleerebezem ${ }^{1,2,6^{*}}$

\begin{abstract}
Background: To cope with environmental challenges bacteria possess sophisticated defense mechanisms that involve stress-induced adaptive responses. The canonical stress regulators CtsR and HrcA play a central role in the adaptations to a plethora of stresses in a variety of organisms. Here, we determined the CtsR and HrcA regulons of the lactic acid bacterium Lactobacillus plantarum WCFS1 grown under reference $\left(28^{\circ} \mathrm{C}\right)$ and elevated $\left(40^{\circ} \mathrm{C}\right)$ temperatures, using ctsR, hrcA, and ctsR-hrcA deletion mutants.

Results: While the maximum specific growth rates of the mutants and the parental strain were similar at both temperatures $\left(0.33 \pm 0.02 \mathrm{~h}^{-1}\right.$ and $0.34 \pm 0.03 \mathrm{~h}^{-1}$, respectively), DNA microarray analyses revealed that the CtsR or HrcA deficient strains displayed altered transcription patterns of genes encoding functions involved in transport and binding of sugars and other compounds, primary metabolism, transcription regulation, capsular polysaccharide biosynthesis, as well as fatty acid metabolism. These transcriptional signatures enabled the refinement of the gene repertoire that is directly or indirectly controlled by CtsR and HrcA of L. plantarum. Deletion of both regulators, elicited transcriptional changes of a large variety of additional genes in a temperature-dependent manner, including genes encoding functions involved in cell-envelope remodeling. Moreover, phenotypic assays revealed that both transcription regulators contribute to regulation of resistance to hydrogen peroxide stress. The integration of these results allowed the reconstruction of CtsR and HrcA regulatory networks in L. plantarum, highlighting the significant intertwinement of class I and III stress regulons.
\end{abstract}

Conclusions: Taken together, our results enabled the refinement of the CtsR and HrcA regulatory networks in L. plantarum, illustrating the complex nature of adaptive stress responses in this bacterium.

Keywords: CtsR, HrcA, Lactobacillus plantarum, Heat, Stress regulons

\section{Background}

Lactic acid bacteria (LAB) are Gram-positive bacteria that occupy a variety of habitats. LAB are acid tolerant and produce lactate as a major metabolic end-product, thereby generating preservative characteristics to fermented foods and beverages. Due to their long history of use in food products, LAB are generally regarded as safe (GRAS) [1,2]. Next to their prominent role in food

\footnotetext{
* Correspondence: Michiel.Kleerebezem@nizo.com

'TI Food \& Nutrition, Nieuwe Kanaal 9A, 6709 PA Wageningen, The Netherlands

${ }^{2} \mathrm{NIZO}$ food research, P.O. Box 20, 6710 BA Ede, The Netherland

Full list of author information is available at the end of the article
}

fermentation, $\mathrm{LAB}$ can be found on plant materials and are among the natural inhabitants of the gastrointestinal (GI) tract of animals and humans [3-5]. Specific Lactobacillus strains are marketed as probiotics which are defined as 'live microorganisms which when administered in adequate amounts confer a health benefit on the host' [6]. The gastrointestinal tract is the site of action where probiotics are predominantly considered to confer these health benefits, where they may inhibit colonization and infection by pathogens, or may strengthen the intestinal epithelial barrier, or modulate immune responses [7]. Probiotics encounter a variety of stresses during industrial production and storage, e.g. temperature shifts and low

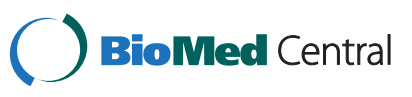


water availability during freeze- or spray-drying, or acid stress during storage. Moreover, during GI passage probiotic bacteria are exposed to acid stress in the stomach, as well as exposure to bile salts and digestive enzymes, while they also have to cope with severe nutrient-competition with the endogenous gut microbiota [8].

To persist under stress conditions, probiotics and LAB in general have an arsenal of molecular defense mechanisms [9-12]. Many stress conditions induce protein denaturation and aggregation, and bacteria, including lactobacilli, possess conserved chaperones and proteases to restore or remove misfolded or denatured proteins. This process has extensively been studied in the paradigm Gram-positive bacterium Bacillus subtilis using abruptly or constantly elevated temperatures as the inducing stress condition. The repertoire of heat shock responses in Bacillus subtilis was stratified in six classes depending on their mode of transcriptional regulation [13-15]. Several of these stress response classes observed in Bacillus subtilis are conserved among the LAB, including the highly conserved Class I regulon. Expression of the Class I stress regulon members is controlled by the repressor HrcA, which specifically binds to the inverted repeat element, CIRCE (controlling inverted repeat for chaperon expression), under non-stressed conditions. The highly conserved CIRCE element (TTAGCACTC-N9-GAGTGCTAA) is typically found in the promoter regions of the $g r o E$ and dnaK operons, which encode the two chaperon complexes GroES-GroEL and HrcA-DnaK-GrpE-DnaJ, respectively [16]. The $h r c A$ gene is commonly part of the dnaK operon, placing this gene under autorepression control. HrcArepression is dependent on the availability of the GroELS complex and is relieved when the GroELS chaperon complex is not available, i.e. during stress conditions when non-native proteins arise [13]. The HrcA regulon is not only induced during heat shock, but is also activated by a variety of other stress conditions, including acid, bile, and salt stress $[9-11,17]$. The genes encompassed within the class III stress regulon appear to be less conserved among LAB, although the class III stress regulon repressor CtsR (class three stress gene repressor) appears to be quite consistently present in these bacteria. However, LAB appear to consistently lack the regulatory adaptor genes encoding for McsB and McsA $[18,19]$. CtsR specifically binds to a heptanucleotide repeat (A/GGTCAAA/T), referred to as the CtsR box [20]. This cis-acting regulatory element is commonly encountered in the promoter regions of $c l p P$ and several other, but not all, clp genes, which encode Clpproteases that are involved in protein quality control during both stress and non-stress conditions [21]. ClpP mediated proteolysis removes misfolded proteins from the cell, but Clp proteases can also function in cellular differentiation processes [21]. In some organisms other transcription regulators, including $\mathrm{HrcA}$, are involved in co-regulation of the CtsR target genes [21,22]. In conclusion, HrcA and CtsR are key components in stress response regulation, which may include cross-regulation between their respective regulons.

Lactobacillus plantarum is encountered in several environmental niches, including fermented foods and the human GI tract, and specific strains are marketed as probiotics [23]. L. plantarum WCFS1, a single colony isolate of strain NCIMB 8826, has been shown to actively survive passage through the human digestive tract [24,25], and it was the first Lactobacillus species of which the complete genome sequence was determined [26]. Besides the genome sequence, advanced functional annotations, as well as sophisticated bioinformatics and mutagenesis tools have been developed, enabling the investigation of generegulatory mechanisms at the molecular level [27-29]. For example, the $h r c A$ and $c t s R$ regulon members could be predicted on basis of the conserved cis-acting elements involved, which has in part been confirmed experimentally [11,30-33]. Some of the HrcA and CtsR regulon members in L. plantarum WCFS1 have been detected through phylogenetic footprinting [32], large scale analysis of co-regulation of expression [33], or via DNA binding assays [30,31]. Moreover, gene-expression responses in L. plantarum have been unraveled for various stress conditions, including lactate [34], low $\mathrm{pH}$ [34], oxidative $[35,36]$, solvent [37,38], bile [39], cold [37], and heat stress [37]. Analysis of available transcriptome data indicates that some but not all of the predicted HrcA and CtsR regulon members of $L$. plantarum WCFS1 are differentially expressed during these different stress challenges [33]. Despite the characterization of these stress responses, the exact regulons of HrcA and CtsR in L. plantarum remain not completely determined.

This paper describes the regulons of CtsR and HrcA at reference and elevated growth temperatures by determination of the whole-genome transcriptome patterns of $c t s R$, $h r c A$, and $c t s R-h r c A$ deletion mutants [38]. The data revealed that the CtsR or HrcA deficient strains displayed altered transcription patterns of genes encoding functions involved in transport and binding of sugars and other compounds, primary metabolism, as well as cell envelope remodeling. Moreover, deficiency of both transcription factors elicited temperature-dependent and pleiotropic transcriptional adaptation of the cell. Finally, stress-phenotyping of the mutants revealed a role of both regulators in the regulation of oxidative stress tolerance.

\section{Materials and methods}

Strains and growth conditions

L. plantarum WCFS1 [26], $\triangle$ ctsR (NZ3410) [38], $\triangle h r c A::$ cat $\left(\mathrm{NZ3425}{ }^{\mathrm{CM}}\right)[38]$, and $\Delta c t s R \Delta h r c A::$ cat $\left(\mathrm{NZ3423}{ }^{\mathrm{CM}}\right)$ [40] were grown in MRS (de Man-Rogosa-Sharpe) broth 
(Difco, West Molesey, United Kingdom) in pH-controlled batch fermentations at $0.5 \mathrm{~L}$ scale in a Multifors miniin parallel fermentor system (Infors-HT Benelux, Doetinchem, the Netherlands). A single colony isolate of L. plantarum WCFS1 or its derivatives was used to inoculate $5 \mathrm{~mL}$ of MRS followed by overnight growth at $37^{\circ} \mathrm{C}$. The full-grown culture was used to prepare a dilution range from $10^{-1}$ to $10^{-6}$ in fresh medium and these dilutions were grown overnight. Subsequently, the culture density was assessed by determination of the optical density at $600 \mathrm{~nm}\left(\mathrm{OD}_{600}\right)$ and the culture that had an $\mathrm{OD}_{600}$ closest to 1.5 (representing logarithmically growing cells) was used to inoculate the fermentors at an initial $\mathrm{OD}_{600}$ of 0.1. During fermentation the cultures were stirred at $125 \mathrm{rpm}$, the $\mathrm{pH}$ of the culture was maintained at 5.8 by titration of $2.5 \mathrm{M} \mathrm{NaOH}$, and temperature was set at $28^{\circ} \mathrm{C}$ or $40^{\circ} \mathrm{C}$. A biologically independent duplicate; i.e., derived from independent colonies and performed on separate days, was included for all strains and temperatures. Cells were harvested at an $\mathrm{OD}_{600}$ of 1.0 for RNA isolation.

\section{RNA isolation and microarray analysis}

RNA extraction, labeling and hybridization, as well as data analysis were performed as described previously $[41,42]$. Briefly, following quenching and cell disruption by bead beating, RNA was isolated using the High Pure kit including $1 \mathrm{~h}$ treatment with DNaseI (Roche Diagnostics, Mannheim, Germany). The resulting RNA was reverse transcribed to obtain cDNAs which were labeled using Cyanine 3 or Cyanine 5 labels (AmershamTM, CyTMDye Post-labelling Reactive Dye Pack, GE Healthcare, UK). The cDNAs were hybridized (Additional file 1: Figure S1) on WCFS1-specific, custom-made Agilent arrays. Each microarray contained at least 2 , but mostly 3 distinct probes for all of the genes detected within the genome. These probes were spotted in duplicate on each array, which was based on the Agilent $15 \mathrm{k}$ format (GEO accession number GPL13984; http://www.ncbi.nlm.nih.gov/geo/). Subsequently, the slides were washed and scanned using routine procedures $[41,42]$ and the obtained transcriptome profiles were normalized using Lowess normalization [43]. The data were corrected for inter-slide differences on the basis of total signal intensity per slide using Postprep [44]. The median intensity of the different probes per gene was selected as the gene expression intensity. This analysis resulted in genome-wide, gene expression levels for L. plantarum WCFS1, NZ3410, NZ3423 ${ }^{\mathrm{CM}}$, and $\mathrm{NZ3425}{ }^{\mathrm{CM}}$. CyberT was used to compare the different transcriptomes [45]. This analysis resulted in a gene expression ratio and false discovery rate (FDR) for each gene. Genes were considered significantly differentially expressed when FDRadjusted p-values were $<0.05$. The DNA microarray data is available under GEO accession number GSE31253.

\section{Data analysis tools}

Visualization of the genes displaying differential expression in the mutants as compared to the wild-type was performed by loading Excel files into the Cytoscape software suite [46]. Data were first ordered using the spring embedded sorting algorithm in the Cytoscape tool. Coloring of the edges (up- or downregulation of the mutants over wild type) and nodes (annotated main class) and structuring of the network were performed manually. The SimPheny ${ }^{\mathrm{TM}}$ software package (Genomatica InC., San Diego, USA) loaded with the L. plantarum WCFS1 genome-scale model [28] was used to visualize differentially expressed genes that encode enzymes in metabolic pathways. Over-represented main classes and subclasses in the transcriptome data were identified using the Biological Networks Gene Ontology (BiNGO) [47] Cytoscape plugin. MEME software [48] was used with default settings to predict conserved cis-acting motifs from 300 nt upstream regions preceding the predicted translation start of the first genes of the operons of all genes. Subsequently, MAST [49] was used to perform genome-wide searches for the MEME-predicted cis-acting elements of HrcA and CtsR [32,33].

\section{Phenotypic assays}

To determine growth efficiency of the different mutant strains, L. plantarum WCFS1 or its derivatives were grown in $\mathrm{MRS}$ at $28^{\circ} \mathrm{C}, 37^{\circ} \mathrm{C}, 40^{\circ} \mathrm{C}$, or $42^{\circ} \mathrm{C}$, and growth was monitored by $\mathrm{OD}_{600}$ measurement during 72 hours (SPECTRAmax PLUS384, Molecular Devices, UK). The maximum specific growth rate was determined by taking the slope of 5 consecutive ln transferred OD data points that gave the highest number. To quantify the colony forming capacity at elevated temperature, the wild type and gene deletion derivatives were grown at $30^{\circ} \mathrm{C}$, serially diluted on MRS agar plates, and incubated for 1 week at $30^{\circ} \mathrm{C}$ or $42^{\circ} \mathrm{C}$. Hydrogen peroxide stress tolerance was measured as described before [38]. In short, PBS washed cultures $\left(\mathrm{OD}_{600}=1.0\right)$ were resuspended in PBS containing $40 \mathrm{mM}$ hydrogen peroxide at RT and samples were taken from this suspension, every $5 \mathrm{~min}$ for $60 \mathrm{~min}$, and colony forming units were enumerated by plating of serial dilutions. Bile resistance was monitored as described before [50]. Briefly, cultures were inoculated in MRS containing $0.1 \%$ porcine bile (Sigma, Zwijndrecht, The Netherlands) at $28^{\circ} \mathrm{C}$ and growth was monitored by $\mathrm{OD}_{600}$ determination (SPECTRAmax PLUS384, Molecular Devices, UK). $\mathrm{H}_{2} \mathrm{O}_{2}$ inactivation data were compared by fitting a reparameterized Weibull model according to Metselaar et al. [51]:

$$
\log _{10}\left(N_{t}\right)=\log _{10}\left(N_{0}\right)-\Delta\left(\frac{t}{t_{\Delta D}}\right)^{\beta}
$$

in which $\Delta$ is the number of decimal reductions, $t_{\Delta D}$ the time needed to reduce the initial number of 
microorganisms with $\Delta$ decimals (min), and $\beta$ a fitting parameter that defines the shape of the curve. $\Delta$ was set at 4 and the other parameters were estimated using Excel 2010. Two-sided Student's $t$-test was used for statistical analysis and $p<0.05$ was considered significant.

\section{Results}

HrcA and CtsR are involved in the heat stress response of $L$. plantarum

HrcA and CtsR are regulators of class I and class III stress responses, respectively, including heat induced stress [13]. The role of these repressors at reference and elevated temperature was investigated in L. plantarum and its previously constructed derivatives that are deficient in either CtsR or HrcA alone, or both [38]. The maximum specific growth rate of the $\Delta c t s R, \triangle h r c A:: c a t$, and $\Delta c t s R \Delta h r c A:: c a t$ strains at 28,37 , and $40^{\circ} \mathrm{C}$ did not differ from the L. plantarum WCFS1 wild-type strain (Figure 1). These findings expand earlier observations demonstrating unaltered growth characteristics of another L. plantarum ctsR mutant relative to its parental strain at $28^{\circ} \mathrm{C}$ [31]. However, although the maximum specific growth rate of $\Delta h r c A:: c a t$ was comparable to the wild-type at $42^{\circ} \mathrm{C}$, the $\Delta c t s R$ and $\Delta c t s R \Delta h r c A:: c a t$ mutants displayed 2.0- and 4.1-fold ( $p<0.001$; Figure 1) decreased specific growth rates, respectively. This result indicates that CtsR is required to sustain normal specific growth rates at $42^{\circ} \mathrm{C}$. When serial dilutions of stationary phase cultures grown at $30^{\circ} \mathrm{C}$ were spotted on MRS plates, followed by continued incubation at $30^{\circ} \mathrm{C}$, the wild-type and mutant strains gave approximately equal numbers of colonies, which were in all cases within the range anticipated for full-grown cultures. This observation indicates

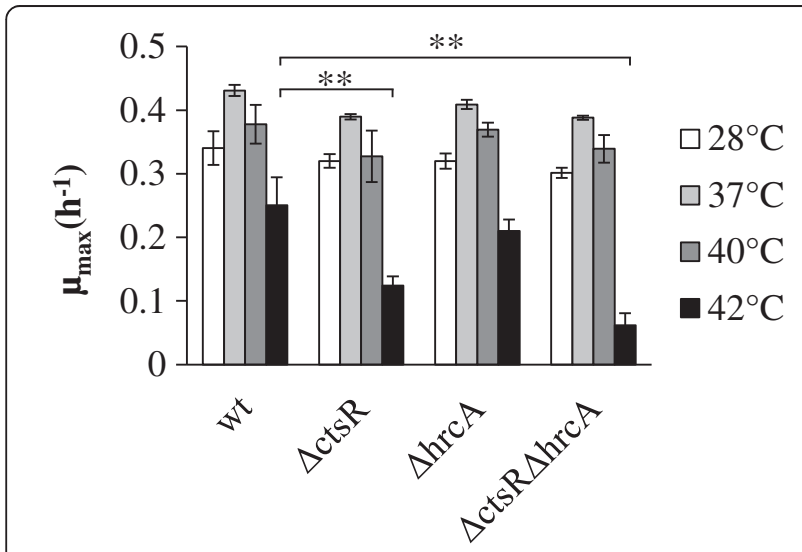

Figure 1 Maximum specific growth rates of $L$. plantarum WCFS1 (wt), NZ3410 ( $\Delta c t s R), \mathrm{NZ}_{42} 5^{\mathrm{CM}}(\Delta h r c A)$, and NZ3423 ${ }^{\mathrm{CM}}$ $(\Delta c t s R \Delta h r c A)$. Specific growth rates are shown for reference $\left(28^{\circ} \mathrm{C}\right)$ and elevated $\left(37^{\circ} \mathrm{C}, 40^{\circ} \mathrm{C}\right.$, and $\left.42^{\circ} \mathrm{C}\right)$ temperatures as indicated in the figure legend. Asterisks indicate $p$-value $<0.001$. Data shown are mean \pm standard deviation of 3 independent experiments. that HrcA and CtsR do not influence the colony forming unit (CFU) numbers of L. plantarum WCFS1 at $30^{\circ} \mathrm{C}$. Notably, when the plates were incubated at $42^{\circ} \mathrm{C}$, the wild type strain generated approximately 100 -fold lower $\mathrm{CFU}$ as compared to incubation at $30^{\circ} \mathrm{C}(p<0.001)$. Importantly, the CFU numbers obtained with the $\Delta c t s R$ mutant were even stronger reduced at $42^{\circ} \mathrm{C}(p<0.001)$, and this effect was even more pronounced for the $\Delta c t s R h r c A:: c a t$ mutant (Figure 2). Conversely, CFU numbers for the mutant lacking a functional $h r c A$ were not significantly different at $30^{\circ} \mathrm{C}$, and $42^{\circ} \mathrm{C}$, indicating that this mutation contributes to increased robustness as compared to the wild-type at this elevated temperature (Figure 2).

\section{Transcriptional response of L. plantarum during heat stress}

To investigate the transcriptional response of $L$. plantarum to elevated temperature and the role of CtsR and HrcA herein, transcriptome profiles of L. plantarum WCFS1 at control and elevated temperatures were determined. The control temperature of $28^{\circ} \mathrm{C}$ and elevated temperature of $40^{\circ} \mathrm{C}$ were selected since $L$. plantarum wild type displays similar specific growth rates at these temperatures as compared to the CtsR and HrcA deficient derivatives (see above). This prevents blurring of the results by genes responding to differential specific growth rates. When comparing the transcriptomes obtained for the wild-type strain at the two temperatures, more than 1000 genes were significantly differentially expressed and 488 genes (exclusive genes with phage and prophage related functions) were more than 2 -fold upregulated or downregulated (Additional file 2: Table S1).

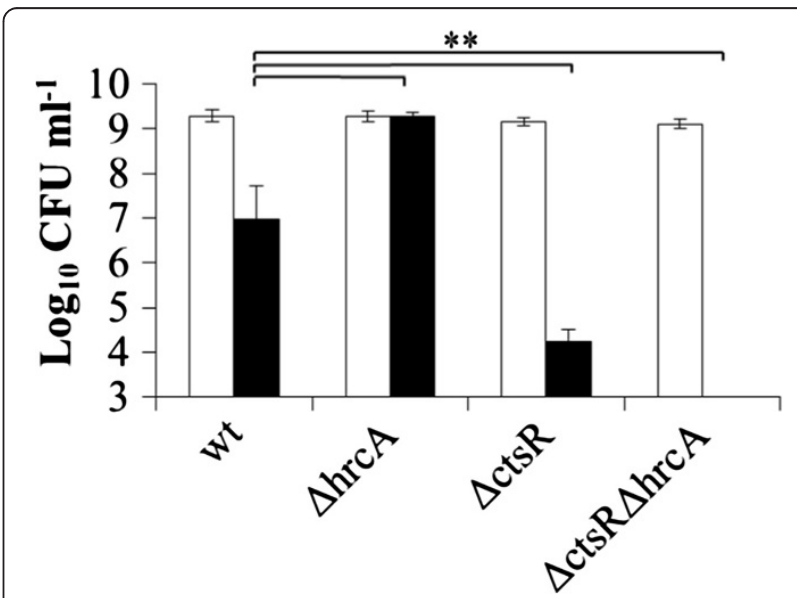

Figure $\mathbf{2}$ Involvement of CtsR and HrcA in the ability to form colonies at elevated temperature. L. plantarum WCFS1 (wt),

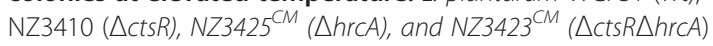
cultures were serial diluted on MRS plates and incubated at control $\left(30^{\circ} \mathrm{C}\right.$; white bars) or elevated temperature $\left(42^{\circ} \mathrm{C}\right.$; black bars).

Asterisks indicate $p$-value $<0.001$. Data shown are mean \pm standard deviation of 3 independent experiments. 
At $40^{\circ} \mathrm{C} h r c A$ expression was reduced, while that of $g r o E L$ and $g r o E S$ were induced. In addition, $\operatorname{clpP}, \operatorname{clpB}$, and $\operatorname{clpE}$, expression levels were induced at the elevated temperature. Of the other (predicted) HrcA or CtsR regulon members (see Table 1) only hsp1 (small heat shock protein 1, which has been shown to be regulated by CtsR [31] and is also predicted to be regulated by HrcA [11]) was induced. In addition, at $40^{\circ} \mathrm{C}$ many genes coding for proteins with regulatory functions were transcribed at an elevated level, suggesting that their regulons contribute to maintenance of normal specific growth rates at this elevated growth temperature, while genes coding for proteins involved in degradation of proteins, peptides, and glycopeptides were repressed. Other transcriptional changes observed at elevated temperature were the downregulation of the capsular polysaccharide (cps)-clusters 1,3, and 4, while many cell surface proteins, including cscII, encoding one of 9 cell surface complexes (lp_2173-lp_2175 (50)) were upregulated. Moreover, the majority of genes required for membrane lipid biosynthesis were down-regulated, including genes encoding fatty acid elongation proteins $(f a b)$, acyl carrier proteins (ACP), and acetyl-CoA carboxylases (ACC). The fab-locus encompasses 13 genes, which were all repressed at least 3.3-fold. In addition, expression levels of $d a k 1 A$, involved in glycerolipid metabolism, and cyclopropanefatty-acyl-phospholipid synthase $(c f a-1)$ were increased, while its paralogue $c f a-2$ was repressed. These results strongly suggest that $L$. plantarum adapts its cell envelope in response to growth at elevated temperature.

\section{Impact of CtsR and HrcA deficiency on expression of their predicted regulons members}

To unravel the role of $\mathrm{HrcA}$ and $\mathrm{CtsR}$ regulation in adaptation to growth at elevated temperatures, we evaluated the transcriptome profiles of the $\Delta c t s R, \triangle h r c A:: c a t$, and $\Delta c t s R \Delta h r c A:: c a t$ mutants grown at $28^{\circ} \mathrm{C}$ and $40^{\circ} \mathrm{C}$ (Figure 3 ). Relative to the wild-type strain, the expression of the $c t s R$ gene was dramatically decreased in the mutants that lack a functional ctsR gene copy (161- to 984-fold), irrespective of the temperature of growth, confirming the integrity of the $c t s R$ mutation in these strains (Table 1). Similarly, $h r c A$ was decreased in the $\Delta h r c A:: c a t$, and $\Delta c t s R \Delta r c A:: c a t$ mutants as compared to the wild type (145- to 241-fold; Table 1). The predicted HrcA and CtsR promoter binding motifs (cis-elements) [32,33] were used for MAST [49] analyses to predict the members of the HrcA and/or CtsR regulons, revealing several genes that appear to harbor the cis-acting motif of at least one of the transcription regulators (Table 1). Several of the CtsR regulon members that have previously been experimentally verified [31], were transcribed at higher levels in the $\Delta c t s R$ and $\Delta c t s R \Delta h r c A:: c a t$ mutants grown at $28^{\circ} \mathrm{C}$ as compared to the wild-type, including $\operatorname{clpP}, \operatorname{clpE}, \operatorname{clpB}, \operatorname{clpC}$, hsp1, and spx 1 (Figure 3 and Table 1). In addition, a gene with unknown function ( $\left.l p \_2061\right)$ and an operon including 2 proteases ( $h s l U$ and $h s l V$ ) were expressed at elevated levels in the $\Delta c t s R$ strain. Of the predicted $h r c A$ regulon members (Table 1), no altered expression pattern was detected for the $g r p E$, dnaK and $d n a J$ genes, which are located in the same operon as $h r c A$, while groEL and groES expression patterns were increased in the $\triangle$ hrcA::cat mutant, at $28^{\circ} \mathrm{C}$. A gene with unknown function (lp_1880) and an integrase/recombinase (lp_1268) were differentially expressed in the $\triangle h r c A:: c a t$ and $\triangle c t s R \Delta h r c A:: c a t$ strains. Remarkably, the $h r c A$ operon seems to have 2 CIRCE elements and a CtsR-targeted cis-element in its promoter region, which may suggest dual control of this regulon by both regulators. However, $h r c A$ was not differentially expressed in the $\Delta c t s R$ mutant at control or elevated temperature. When identifying possible dually regulated genes, only hsp1 had CtsR and HrcA cis-acting elements in the promoter region of this gene (Table 1), as was described previously [11]. This was supported by the upregulation of this gene in all three mutants compared to wild type at $28^{\circ} \mathrm{C}$ (Figure $3 \mathrm{~A}$ and Table 1 ). It might be that sequence or position of the cis-acting elements matches with their expression level in the mutants. However, no significant correlation could be detected. Together this indicates that the deregulation of class I and/ or class III stress responses by mutation of their regulators induces a partial alteration of expression of their (predicted) regulon members under the conditions tested. Besides the predicted regulon members, the transcription of genes classified to various functional categories appeared to be affected by $c t s R$ and/or $h r c A$ mutation, which will be discussed below.

\section{HrcA and CtsR mutation affect expression of genes encoding proteins with diverse functions}

Additional genes coding for proteins from several functional categories were displaying altered transcription levels in the $\Delta h r c A:: c a t$ and $\Delta c t s R$ mutants as compared to the wild type. The $h r c A$ mutation led to induced transcription of 29 transcription regulator encoding genes, including transcription regulators belonging to the AraC, LysR, MarR and TetR/AcrR family regulators. Several genes involved in primary metabolism were induced in the $\Delta c t s R$ strain compared to the wild type. These genes were involved in a variety of central metabolism reactions, centering around pyruvate dissipation and fermentation related reactions, including pox, pfl, pdh, pps, mae, als, and cit (Figure 4; abbreviations are addressed in the Additional file 3:Table S2). In addition, genes involved in pentose-5-phosphate pathway, producing D-xylulose-5-phosphate, which can be used for nucleotide synthesis or energy production, (including $x p k A$, $t k t 1$, deoM, rpiA1, gntK, and $x f p$ ) were induced in the $\Delta c t s R$ strain compared to the wild type (Figure 4). 
Table 1 Fold-changes of predicted and verified CtsR and HrcA regulon members ${ }^{\mathrm{a}}$ in the NZ3410 $(\Delta c t s R), N Z 3425^{\mathrm{CM}}$

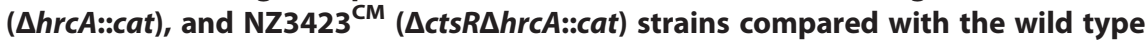

\begin{tabular}{|c|c|c|c|c|c|c|c|c|c|}
\hline \multirow[t]{2}{*}{$I^{b}$} & \multirow[t]{2}{*}{ Name } & \multirow[t]{2}{*}{ Function } & \multirow[t]{2}{*}{$p$-value ${ }^{c}$} & \multicolumn{3}{|l|}{$28^{\circ} \mathrm{C}$} & \multicolumn{3}{|l|}{$40^{\circ} \mathrm{C}$} \\
\hline & & & & $\Delta c t s R$ & $\Delta h r c A$ & $\Delta c t s R \Delta h r c A$ & $\Delta c t s R$ & $\Delta h r c A$ & $\Delta c t s R \Delta h r c A$ \\
\hline \multicolumn{10}{|l|}{ CtsR } \\
\hline Ip_0786 & $C l p P$ & Endopeptidase Clp, proteolytic subunit & & $2.42^{d}$ & -1.09 & 2.33 & 1.27 & -1.29 & 1.12 \\
\hline Ip_1269 & $c \mid p E$ & ATP-dependent Clp protease, ATP-binding subunit ClpE & $2.0 \cdot 10^{-10}$ & 2.27 & -1.02 & 2.12 & -1.01 & -1.20 & -1.12 \\
\hline Ip_1903 & $C l p B$ & ATP-dependent Clp protease, ATP-binding subunit ClpB & $5.0 \cdot 10^{-10}$ & 7.01 & 1.00 & 6.92 & 4.24 & -1.33 & 3.71 \\
\hline Ip_1018 & $\operatorname{cts} R$ & transcription repressor of class III stress genes & & -696 & -1.15 & -984 & -526 & -1.31 & -161 \\
\hline Ip_1019 & $c l p C$ & ATP-dependent Clp protease, ATP-binding subunit ClpC & & 1.92 & -1.09 & 1.84 & 1.76 & -1.30 & 1.58 \\
\hline Ip_0129 & hsp1 & Small heat shock protein & $3.9 \cdot 10^{-11}$ & 5.57 & 3.16 & 12.70 & 1.12 & -1.38 & 1.21 \\
\hline Ip_2945 & Ip_2945 & Aromatic acid carboxylyase, subunit C (putative) & $3.5 \cdot 10^{-10}$ & 1.27 & -1.08 & 1.57 & 1.21 & 1.20 & 1.46 \\
\hline Ip_2451 & Ip_2451 & Prophage P2a protein 6; endonuclease & $4.9 \cdot 10^{-7}$ & 1.05 & 1.11 & 1.12 & 1.03 & 1.40 & 1.32 \\
\hline Ip_2926 & IP_2926 & Unknown & $2.8 \cdot 10^{-6}$ & 1.08 & -1.08 & -1.10 & 1.30 & -1.19 & 1.05 \\
\hline Ip_2426 & Ip_2426 & $\begin{array}{l}\text { Prophage P2a protein 31; phage transcriptional regulator, } \\
\text { ArpU family }\end{array}$ & $2.8 \cdot 10^{-6}$ & -1.18 & -1.56 & -2.07 & 8.85 & -1.87 & 1.31 \\
\hline Ip_2540 & IP_2540 & Unknown & $4.0 \cdot 10^{-6}$ & 1.09 & -1.31 & 4.11 & -1.27 & 1.27 & -1.14 \\
\hline Ip_2541 & IP_2541 & $A B C$ transporter, substrate binding protein & $4.0 \cdot 10^{-6}$ & -1.15 & -1.03 & 1.01 & 1.07 & 1.31 & 1.44 \\
\hline Ip_2542 & Ip_2542 & $\mathrm{ABC}$ transporter, permease protein (putative) & $4.0 \cdot 10^{-6}$ & -1.03 & -1.12 & -1.06 & -1.02 & 1.09 & 1.15 \\
\hline Ip_2543 & Ip_2543 & ABC transporter, ATP-binding protein & $4.0 \cdot 10^{-6}$ & -1.18 & 1.02 & 1.27 & -1.14 & 1.15 & 1.01 \\
\hline Ip_3530 & trep & Trehalose phosphorylase & $4.0 \cdot 10^{-6}$ & -1.20 & -1.25 & -1.05 & 2.30 & -1.32 & -1.13 \\
\hline Ip_2061 & Ip_2061 & Unknown & $4.0 \cdot 10^{-6}$ & 1.38 & 1.53 & 1.47 & -1.21 & 1.10 & 1.07 \\
\hline Ip_2029 & hrcA & Heat-inducible transcription repressor HrcA & $5.8 \cdot 10^{-6}$ & -1.32 & -241 & -147 & 1.15 & -176 & -145 \\
\hline Ip_2028 & grpE & Heat shock protein GrpE & $5.8 \cdot 10^{-6}$ & -1.04 & 1.48 & 1.23 & -1.21 & 1.26 & -1.27 \\
\hline Ip_2027 & dnak & Chaperone, heat shock protein Dnak & $5.8 \cdot 10^{-6}$ & -1.23 & 1.30 & 1.16 & -1.28 & 1.09 & -1.43 \\
\hline Ip_2842 & Ip_2842 & Transcription regulator, LysR family & $6.7 \cdot 10^{-6}$ & 1.08 & 1.14 & -1.04 & -1.17 & -1.34 & 1.03 \\
\hline Ip_1843 & Ip_1843 & Aldose 1-epimerase family protein & $9.8 \cdot 10^{-6}$ & -1.06 & -1.14 & 1.06 & 1.50 & 1.19 & 1.20 \\
\hline Ip_1845 & hslU & ATP-dependent Hsl protease, ATP-binding subunit HsIU & $9.8 \cdot 10^{-6}$ & 1.10 & -1.02 & 1.23 & 1.65 & 1.08 & 1.44 \\
\hline Ip_1846 & hs $/ V$ & ATP-dependent protease HsIV & $9.8 \cdot 10^{-6}$ & 1.16 & 1.14 & 1.31 & 1.78 & 1.11 & 1.50 \\
\hline Ip_1847 & Ip_1847 & Integrase/recombinase, XerC/CodV family & $9.8 \cdot 10^{-6}$ & 1.22 & 1.22 & 1.36 & 1.73 & 1.11 & 1.36 \\
\hline \multicolumn{10}{|l|}{ HrcA } \\
\hline Ip_0727 & groEL & GroEL chaperonin & $5.9 \cdot 10^{-9}$ & -1.19 & 2.00 & 1.59 & -1.46 & 1.06 & -1.50 \\
\hline Ip_0728 & groEs & GroES co-chaperonin & $5.9 \cdot 10^{-9}$ & -1.21 & 2.13 & 1.62 & -1.55 & 1.14 & -1.50 \\
\hline Ip_2029 & $\operatorname{hrcA^{f}}$ & Heat-inducible transcription repressor $\mathrm{HrcA}$ & $2.9 \cdot 10^{-14}$ & -1.32 & -241 & -147 & 1.15 & -176 & -145 \\
\hline Ip_2028 & grpE & Heat shock protein GrpE & $2.9 \cdot 10^{-14}$ & -1.04 & 1.48 & 1.23 & -1.21 & 1.26 & -1.27 \\
\hline Ip_2027 & dnak & Chaperone, heat shock protein DnaK & $2.9 \cdot 10^{-14}$ & -1.23 & 1.30 & 1.16 & -1.28 & 1.09 & -1.43 \\
\hline Ip_2026 & dna & Chaperone protein DnaJ & & -1.13 & 1.05 & 1.17 & -1.07 & 1.08 & 1.14 \\
\hline Ip_0726 & Ip_0726 & Membrane-bound protease, CAAX family & $1.0 \cdot 10^{-7}$ & 1.90 & -1.07 & 1.56 & 2.26 & -1.22 & 2.44 \\
\hline Ip_0129 & hspl & Small heat shock protein & & 5.57 & 3.16 & 12.70 & 1.12 & -1.38 & 1.21 \\
\hline Ip_0413 & $p \ln Q$ & Plantaricin biosynthesis protein PInQ & $6.9 \cdot 10^{-7}$ & -1.03 & 1.23 & 1.51 & -2.14 & -1.16 & 1.16 \\
\hline Ip_3578 & kat & Catalase & $1.0 \cdot 10^{-6}$ & 1.02 & 1.02 & 1.03 & 1.28 & -1.20 & -1.13 \\
\hline Ip_3617 & tal3 & Transaldolase & $1.7 \cdot 10^{-6}$ & -1.19 & -1.04 & 1.22 & 1.26 & 1.14 & -1.28 \\
\hline Ip_3618 & pts37A & Sorbitol PTS, ElIA & $1.7 \cdot 10^{-6}$ & 1.03 & 1.02 & 1.33 & 4.51 & 1.33 & 1.26 \\
\hline Ip_3619 & pts37BC & Sorbitol PTS, EIIBC & $1.7 \cdot 10^{-6}$ & 2.15 & 1.31 & 2.50 & 2.68 & -1.40 & -1.23 \\
\hline Ip_3620 & pts37C & Sorbitol PTS, EIIC & $1.7 \cdot 10^{-6}$ & 1.00 & -1.33 & -1.10 & 1.88 & 1.19 & 1.46 \\
\hline |p_3621 & srlM1 & Sorbitol operon activator & $1.7 \cdot 10^{-6}$ & 1.39 & 1.17 & 2.13 & 2.22 & 1.08 & 1.40 \\
\hline Ip_3622 & $s r l R 1$ & Sorbitol operon transcription antiterminator, BglG family & $1.7 \cdot 10^{-6}$ & -1.36 & -1.13 & -1.05 & 2.17 & 1.01 & 1.30 \\
\hline
\end{tabular}


Table 1 Fold-changes of predicted and verified CtsR and HrcA regulon members ${ }^{\mathrm{a}}$ in the NZ3410 $(\Delta c t s R), N Z 3425^{\mathrm{CM}}$

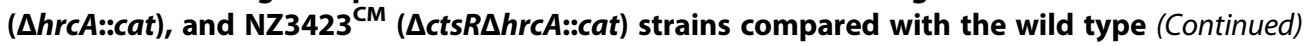

\begin{tabular}{|c|c|c|c|c|c|c|c|c|c|}
\hline Ip_3623 & srlD1 & Sorbitol-6-phosphate 2-dehydrogenase (EC 1.1.1.140) & $1.7 \cdot 10^{-6}$ & -1.10 & -1.35 & -1.43 & 1.37 & -1.16 & 1.88 \\
\hline Ip_1268 & Ip_1268 & Integrase/recombinase & $3.7 \cdot 10^{-6}$ & -2.21 & -1.10 & -1.56 & -3.07 & 1.49 & -3.38 \\
\hline |p_0387 & Ip_0387 & Unknown & $2.4 \cdot 10^{-6}$ & 1.18 & 1.04 & 1.25 & 1.06 & -1.00 & 1.35 \\
\hline Ip_1879 & hbsU & DNA-binding protein & $9.9 \cdot 10^{-6}$ & -1.14 & 1.04 & -1.14 & -1.23 & 1.04 & -1.27 \\
\hline Ip_1880 & Ip_1880 & Unknown & $9.9 \cdot 10^{-6}$ & -1.13 & 1.11 & -1.14 & -1.59 & 1.20 & -1.71 \\
\hline
\end{tabular}

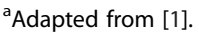

${ }^{\mathrm{b}}$ The Ip_number indicates gene number on L. plantarum WCFS1 chromosome [2].

${ }^{c} p$-value of the best match on the upstream sequence after comparing the canonical regulatory factor binding site. Values lower than $1.0 \cdot 10^{-5}$ were included. ${ }^{d}$ Fold-changes in bold are significant (FDR adjusted $p$-value $<0.05$ )

${ }^{\mathrm{e}}$ The cis-element is predicted to be in front of this operon that contains $I p \_2426$ until Ip_2431, which all encode proteins of prophage P2a. Fold-changes are only given for I $p \_2426$.

The upstream region of $h r c A$ contains two CIRCE elements. The second has a $p$-value of $8.3 \cdot 10^{-9}$.

Moreover, genes involved in sugar metabolism, such as $\operatorname{scr} B$ (sucrose), pbg (glucose), lac (galactose), ara (ribulose), and iol (inositol), were induced in this strain, as were genes involved in transport of other unspecified carbohydrate substrates and organic acids. These genes included sucrose (pts26BCA), glucose (pts32), maltodextrin ( $m d x$, $m s m X)$, mannitol (pts2A), mannose (lp_3643, pts9), arabinose (araP), trehalose (pts $4 A B C)$ and sorbitol (pts37A, pts38BC) transporters. These results illustrate the impact of CtsR deregulation on the expression of metabolic genes, mainly affecting functions of primary carbohydrate import and central metabolic pathways, which was not observed in the $h r c A$-deficient strain. Nevertheless, the $h r c A$-mutation led to repression of genes involved in transport and binding functions, like those involved in transport of phosphate (pst), amino acids (cho, sdA, lp_1722, and $\left.l p \_3324\right)$, and unknown substrates. Taken together these observations illustrate that deregulation of CtsR or HrcA elicits different response-profiles of transport and metabolism functions.

In addition, the mutations of $h r c A$ and/or $c t s R$ appeared to play a role in the control of expression of some of the genes and functions that were affected by the temperature of growth in the wild-type strain (see above). Temperature-mediated regulation appeared to be (partially) lost in the $\Delta c t s R$ mutant (cps1), in the $\triangle h r c A:: c a t$ mutant (fab operon, $\operatorname{dak} 1 A$, and $c f a 2$ ), or in the $\Delta c t s R \Delta h r c A:: c a t$ mutant [lp_0988 (lipoprotein precursor), cps1, and $c f a 2$ ] compared to that seen in the wild-type strain (Figure 5). This indicates that inactivation of both class I and III transcription regulation leads to deregulation of different combinations of cell envelope biosynthesis processes compared to deregulation of one of the regulators in a temperaturedependent way. Taken together, these findings indicate that some of the more prominent adaptations that the wild-type strain employs to combat elevated growth temperatures, appear to be deregulated in the HrcA and CtsR mutant strains.

\section{Combined HrcA and CtsR deficiency elicits pleiotropic deregulation of the stress control network}

To characterize the gene-regulation consequences of the $h r c A$ and $c t s R$ single mutation relative to the double mutation, the significant regulatory profiles were reconstructed in gene-regulation networks for these strains relative to the wild-type strain at both $28^{\circ} \mathrm{C}$ (Figure 3A) and $40^{\circ} \mathrm{C}$ (Figure $3 \mathrm{~B}$ ). A relatively large number of genes displayed significant differential expression when comparing the $\Delta c t s R \Delta h r c A:: c a t$ and wild type strains grown at either $28^{\circ} \mathrm{C}$ (513 genes) or $40^{\circ} \mathrm{C}\left(603\right.$ genes). At $28^{\circ} \mathrm{C}$, these genes included almost all differentially expressed genes of the $\triangle c t s R$ and $\triangle h r c A:: c a t$ strains (Figure 3A). Conversely, less than one quarter and less than one third of the genes differentially expressed in the double mutant at $28^{\circ} \mathrm{C}$ were affected in the $c t s R$ and $h r c A$ single mutation at $40^{\circ} \mathrm{C}$, respectively. Genes that are not differentially expressed in the other mutants than the $\Delta c t s R$ strain comprised for instance induction of energy metabolism (genes associated with TCA cycle, sugars, and glycolysis) and transport and binding proteins (e.g. the PTS system) and comprised 24 genes associated with regulatory functions for the $\triangle h r c A:: c a t$ strain. Overlapping genes of the ctsR or $h r c A$ single mutation grown at $40^{\circ} \mathrm{C}$ with the double mutant grown at both temperatures included genes associated with the pentose phosphate pathway ( $t k t 1 A$ and $t k t 1 B$ ) and cell division (ftsQ, parB1, parA, and parB2), for the $c t s R$ mutation and included genes associated with transport and binding proteins (e.g. ABC transporters and multidrug transporter proteins) for the $h r c A$ mutation. In addition, genes associated with the cell envelope (such as genes encoding cell surface proteins and genes involved in fatty acid biosynthesis) were differentially expressed in all three mutants at $40^{\circ} \mathrm{C}$. All three mutants affect temperature-independently the $\operatorname{dak} 1 B$ operon that is involved in glycerolipid metabolism. Moreover, approximately one third of the genes appeared to be consistently affected by the $\Delta c t s R \Delta h r c A:: c a t$ mutation at both growth temperatures. The genes consistently affected by 

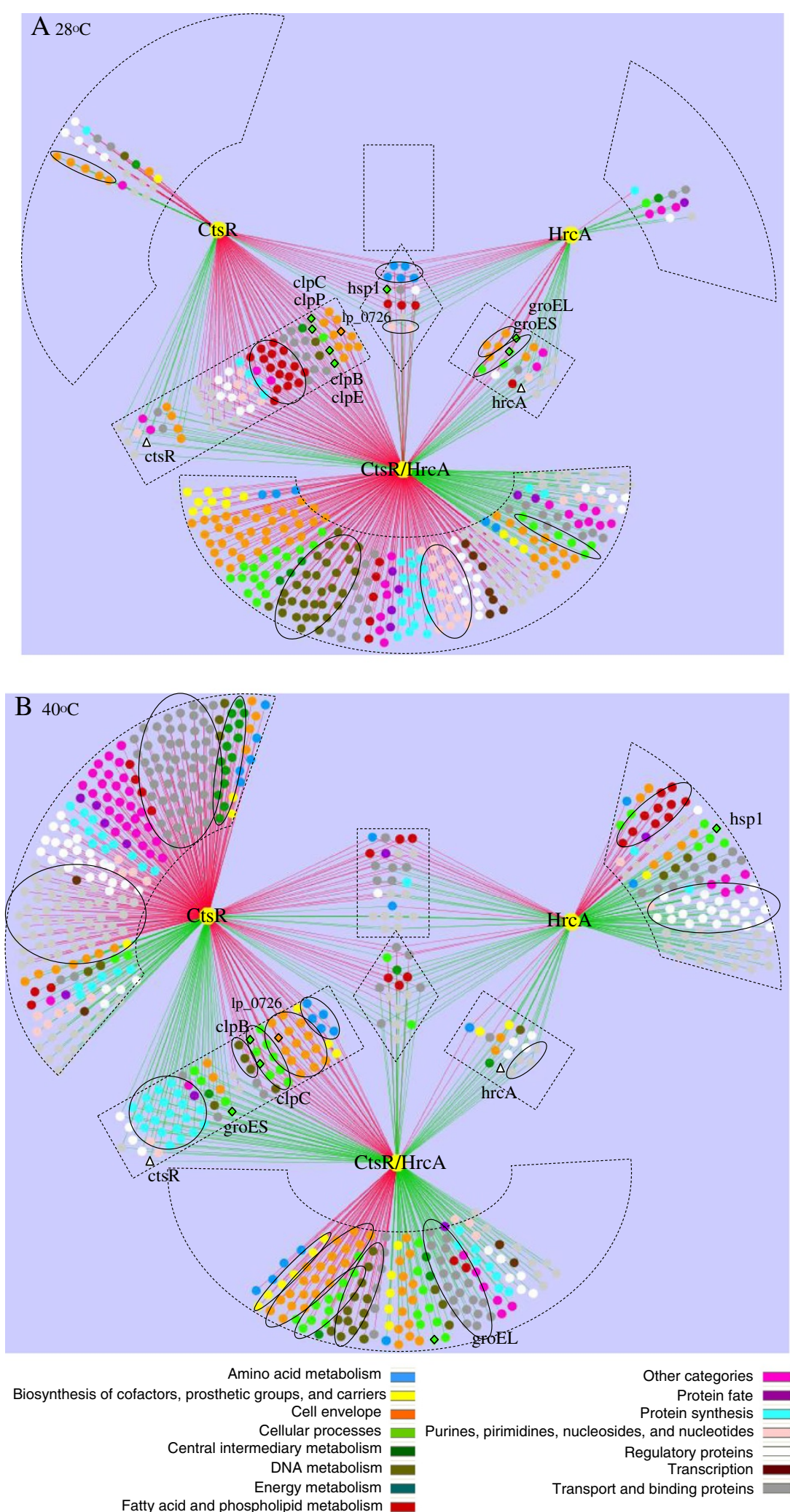

Figure 3 (See legend on next page.) 
(See figure on previous page.)

Figure 3 Significantly differentially transcribed genes in NZ3410 ( $\Delta c t s R), \mathrm{NZ3425} 5^{\mathrm{CM}}(\Delta h r c A)$, and NZ3423 ${ }^{\mathrm{CM}}(\Delta c t s R \Delta h r c A)$ as compared to the wild-type grown at $28^{\circ} \mathrm{C}(\mathrm{A})$ or $40^{\circ} \mathrm{C}$ (B). Yellow colored octangular nodes represent the mutants and other colored nodes indicate main classes. The red and green lines indicate up- or downregulation, respectively. Triangle nodes indicate the CtsR or HrcA transcription regulator, diamond nodes indicate genes that are predicted to be part of the CtsR and/or HrcA regulon, whereas black ovals indicate over-represented main classes or subclasses in that particular main class. The main class "hypothetical proteins" was excluded.

the $\Delta c t s R \Delta h r c$ :::cat mutation included induction of genes associated with the cellular processes (such as cell division protein-encoding genes fts $Z$, fts $A$, and $f t s Q$ ), DNA metabolism (DNA ligase ligA, DNA helicase $p c r A$, and DNA-directed DNA polymerase I polA), transport and binding proteins $\left(\mathrm{Na}^{+} / \mathrm{H}^{+}\right.$antiporter napA2, mannose PTS pts9D, and $10 \mathrm{ABC}$ transporters), and cell envelope remodeling (cps-cluster 1, fab-locus, lipoprotein precursors $l p \_1146$ and $\left.l p \_1539\right)$.

To further analyze the transcriptome profile of the $\Delta c t s R \Delta h r c A:: c a t$ mutant grown at $28^{\circ} \mathrm{C}$ and $40^{\circ} \mathrm{C}$, overrepresentative functional classes were identified (Figure 3 ). The BiNGO analysis tool was used to compare the $\Delta c t s R \Delta h r c A:: c a t$ strain to the wild type, indicating that functional classes associated with cell envelope remodeling were induced, including the main class "cell envelope" with the sub-class "surface polysaccharides, lipopolysaccharides and antigens", which were induced at both temperatures of growth. In addition, the main classes "cellular processes" and "DNA metabolism" were temperatureindependently induced. Temperature specific cell envelope remodeling was also apparent from over-representation of the main class "fatty acid and phospholipid metabolism" when grown at $28^{\circ} \mathrm{C}$, while several subclasses of cell surface proteins ("LPxTG anchored", "membrane bound", and "other") were over-represented at $40^{\circ} \mathrm{C}$. The main class "protein synthesis" was reduced in the $c t s R$ and $h r c A$ deficient strain only when grown at $40^{\circ} \mathrm{C}$ (Figure 3). Taken together, these data indicate that the cell employs highly adaptable, temperature-dependent systems involving many cell envelope associated functional classes to compensate for the absence of CtsR and HrcA regulation and that the expression of a large variety of additional genes appeared to be modulated compared to deregulation of one of the transcription factors.

\section{HrcA and/or CtsR are required for hydrogen peroxide resistance regulation in $L$. plantarum}

Besides involvement of CtsR and HrcA to combat temperature stress, it is known that the transcription factors are associated with other stresses. To evaluate whether $c t s R$ and/or $h r c A$ may be involved in gastrointestinal (GI)-tract survival, the overlap between the differentially expressed genes in the constructed mutant and the genes identified as being induced in the murine intestine [52] were compared, revealing a substantial overlap (26\%) with the genes that were induced in the ctsR deletion mutant compared to the wild type grown at $40^{\circ} \mathrm{C}$. In addition, L. plantarum WCFS1 genes differentially expressed in response to porcine bile exposure [53], were also affected by the $c t s R$ gene deletion when grown at $40^{\circ} \mathrm{C}(27 \%)$, albeit in the opposite direction. The possible role(s) of CtsR and/or HrcA in bile-stress response and tolerance was investigated by determination of the relative bile-tolerance of the three mutants relative to the wild type, revealing no significant role of either $c t s R$ or $h r c A$ in growth in the presence of bile (MRS containing $0.1 \%$ porcine bile; data not shown), suggesting that the $c t s R$ and $h r c A$ regulators do not play a role in bile tolerance. Although we cannot rule out the occurrence of polar effects that may have altered the expression some genes. In addition, the 3 mutant strains also displayed similar survival characteristics as the wild type in an in vitro assay that aims to mimic conditions encountered in the GI-tract [40]. Overall, these data suggest that although deregulation of CtsR and HrcA affects the expression of genes that were also differentially expressed under conditions relevant for the GI-tract, no experimental support could be found for a role of the $c t s R$ and/or $h r c A$ responses in survival under these conditions.

Another comparison between gene expression profiles of the $\Delta c t s R \Delta h r c A:: c a t$ strain grown at $28^{\circ} \mathrm{C}$ and the response of $L$. plantarum to hydrogen peroxide [36], also revealed overlapping responses (21\%). Analogous to what was observed for the bile responses (see above), the direction of gene expression changes were opposite for a number of genes affected both by $\mathrm{H}_{2} \mathrm{O}_{2}$ exposure, i.e., $\mathrm{H}_{2} \mathrm{O}_{2}$ induced expression of lp_1163, dak1B, dak2, dak3, $l p \_1539$, the cps1-cluster and the $\Delta c t s R \Delta h r c A:: c a t$ mutation elicited their repression. To evaluate the potential involvement of $c t s R$ and $h r c A$ in the oxidative-stress response and cognate tolerance towards $\mathrm{H}_{2} \mathrm{O}_{2}$ exposure, the wild type and mutant strains were grown to the exponential phase of growth $\left(\mathrm{OD}_{600}\right.$ of 1.0) and their rate of loss of survival upon lethal $\mathrm{H}_{2} \mathrm{O}_{2}$ exposure ( $40 \mathrm{mM} \mathrm{H}_{2} \mathrm{O}_{2}$ [54]), was followed over time by enumeration of colony forming units (Figure 6A). Compared to the wild-type strain, the $\Delta c t s R$ strain displayed similar rates of loss of survival, while the $\Delta h r c A:: c a t$ and especially the $\Delta c t s R \Delta h r c A::$ cat strain were substantially reduced in their capability to tolerate $\mathrm{H}_{2} \mathrm{O}_{2}$ compared to the wild-type strain. This was already apparent after relatively short exposure to lethal peroxide stress levels, as is illustrated by the 10 -fold reduced viability of the $\Delta c t s R \Delta h c A:: c a t$ strain after $10 \mathrm{~min}$ exposure to peroxide relative to the wild-type (Figure 6A). 


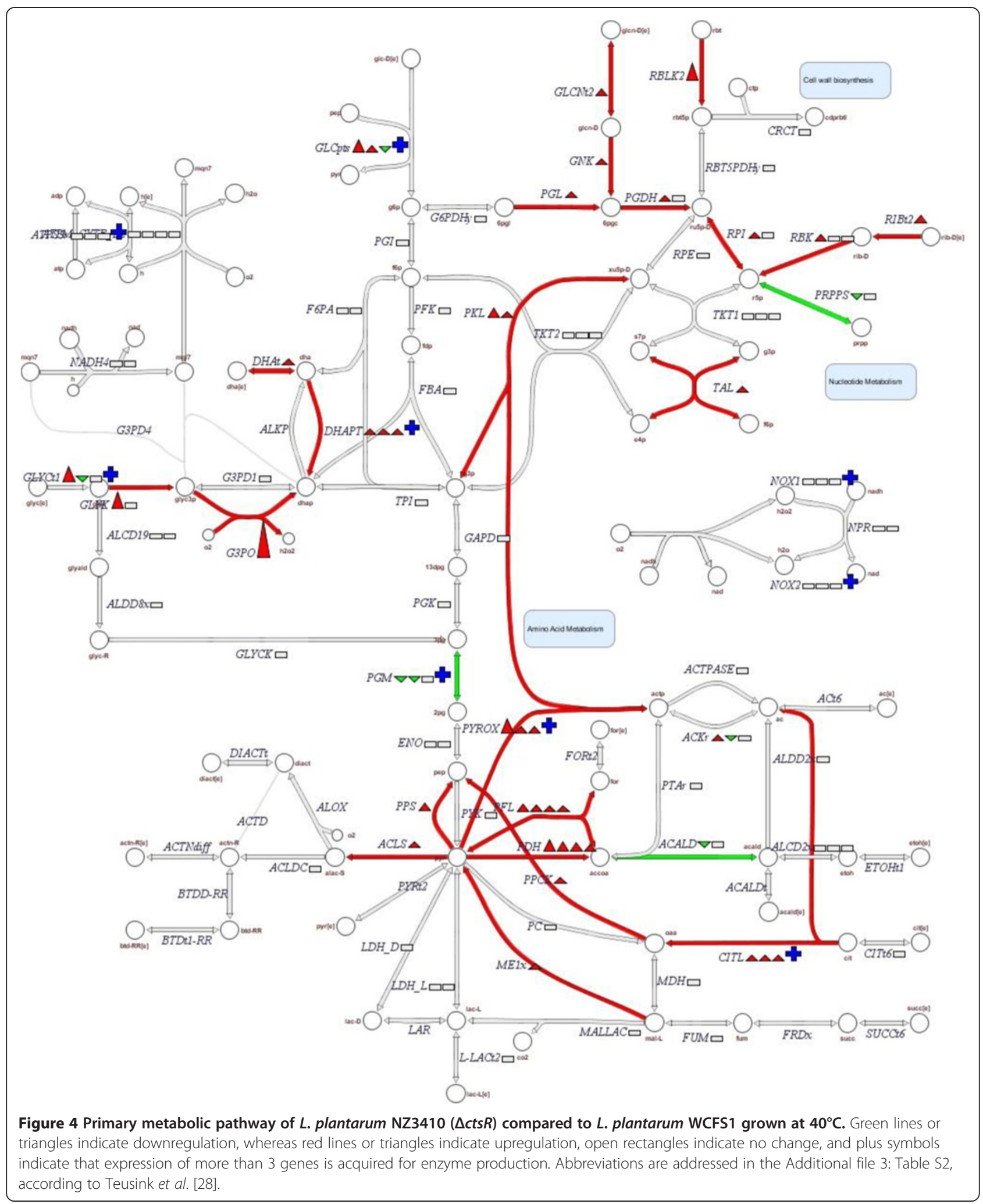

To quantitatively compare the data, a reparameterized Weibull model was fitted to the inactivation data according to Metselaar et al. [51]. In this adjusted Weibull model, the time to the first 4 decimal reductions $\left(t_{4 D}\right)$ was calculated (Figure 6B). Shaping parameter $\beta$ was comparable between the wild type and the variants, ranging from 2.20 to 3.42 . 

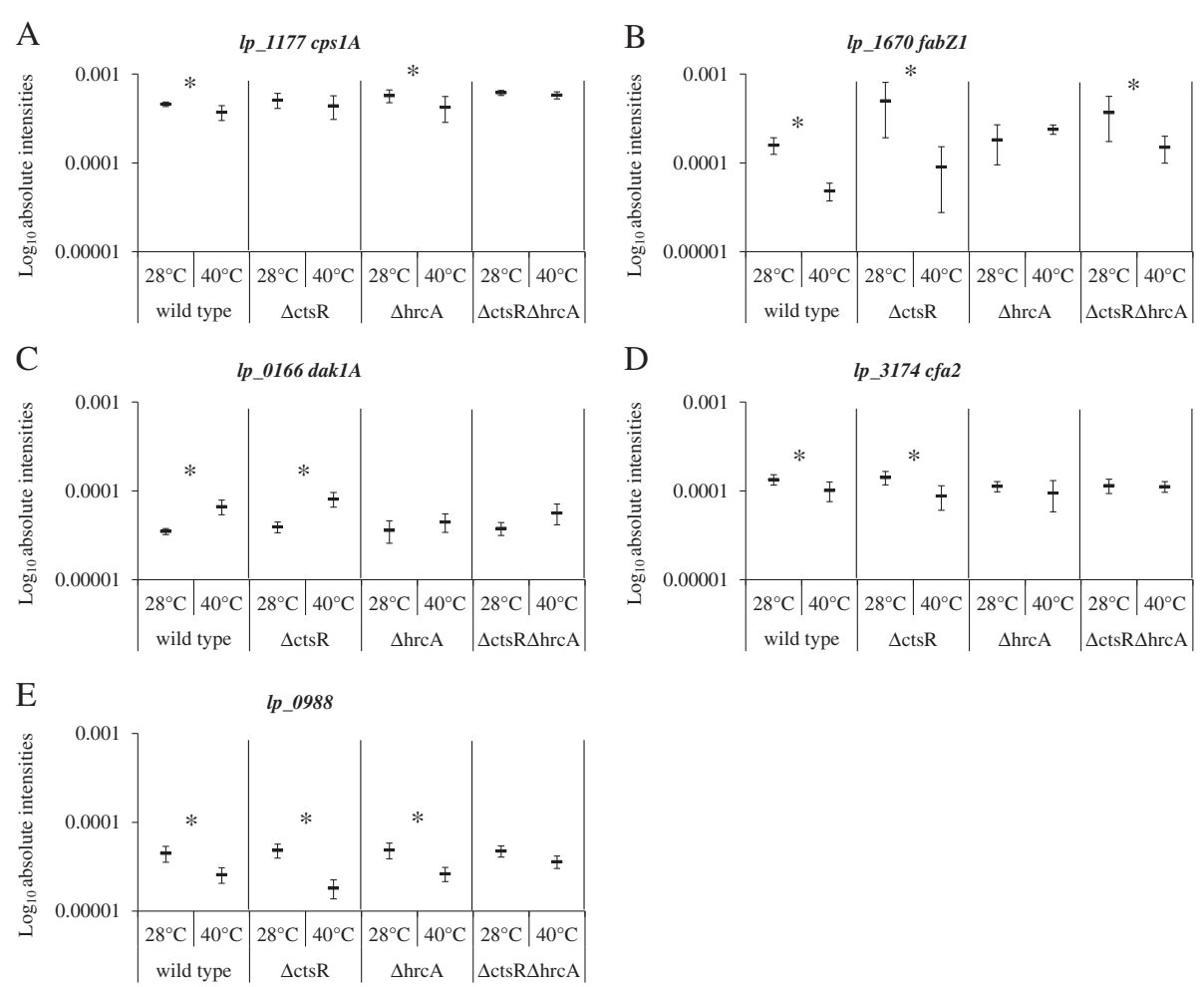

Figure 5 Box plots displaying the absolute intensity of the first gene of the $c p s$ cluster $1\left(I p \_1177 ; A\right)$, the fab-operon $\left(I p \_1670 ; B\right)$, dak1A (Ip_0166; C), cfa2 (Ip_3174; D), and Ip_0988 (E) of L. plantarum WCFS1 (wild type), NZ3410 ( $\Delta c t s R), \mathrm{NZ3425}^{\mathrm{CM}}(\Delta h r C A)$, and NZ3423 ${ }^{\mathrm{CM}}$ ( $\triangle$ ctsRAhrcA) grown at $28^{\circ} \mathrm{C}$ or $40^{\circ} \mathrm{C}$. Asterisk indicates that (part) of the loci are significant differentially expressed when compared to the strains growth at the other temperature.

The $\Delta c t s R \Delta h r A:: c a t$ strain showed a significant lower $t_{4 D}$ compared to the wild type (Figure 6B). In conclusion, these data underline that deregulation of the HrcA and CtsR regulons influences $\mathrm{H}_{2} \mathrm{O}_{2}$ tolerance.

\section{Discussion}

In this paper, transcriptome profiles of $L$. plantarum WCFS1 were determined at reference and elevated temperatures. In the wild type strain, elevated temperature induced relatively major alterations in gene expression patterns. Many of these alterations suggest that adaptation of the cell envelope architecture is among the most important adaptive responses to elevated temperature. Relative to growth at $28^{\circ} \mathrm{C}$, growth at $40^{\circ} \mathrm{C}$ induced the expression of several of the predicted CtsR and/or HrcA regulon members, e.g., groES, groEL, $c l p P, \operatorname{clpB}, c l p E$, and $h s p 1$ [32,33]. This is in accordance with a study by Russo et al. that performed a global proteomic analysis of $L$. plantarum WCFS1 and a $\Delta c t s R$ mutant strain under optimal and heat stressed conditions [55]. Growth characteristics of the HrcA and CtsR deficient strains were considerably different from those of the wild-type, which was especially apparent from the mutants' phenotype at $42^{\circ} \mathrm{C}$. At this temperature, CtsR appeared to be required for maximum specific growth rates, while $\mathrm{HrcA}$ deletion increased colony forming capacity. Although the mechanism underlying the latter observation remains to be elucidated, it is most likely explained by culturerobustness heterogeneity, which in the $h r c A$ deletion strain had shifted towards an average higher robustness level. While in several other organisms, ctsR mutation has been shown to enhance survival under stress conditions [56-59] this seemed not to be the case for L. plantarum, which is in agreement with previous studies in this organism [31]. Conversely, the enhanced colony forming capacity of the $h r c A$ mutant at $42^{\circ} \mathrm{C}$ can be related to the deregulation of the class I stress response network, which is in agreement with the observation that similar mutations in other species enhanced their robustness under stress conditions [59,60]. However, in Listeria monocytogenes, hrcA deletion is suggested to be associated with increased heat sensitivity [61]. Overall, the impact of deregulation of the class I and class III stress responses on bacterial robustness is not very consistent and seems to vary considerably between species, which implies that extrapolation of the results obtained in specific species or strains to other organisms should be performed with great care. 


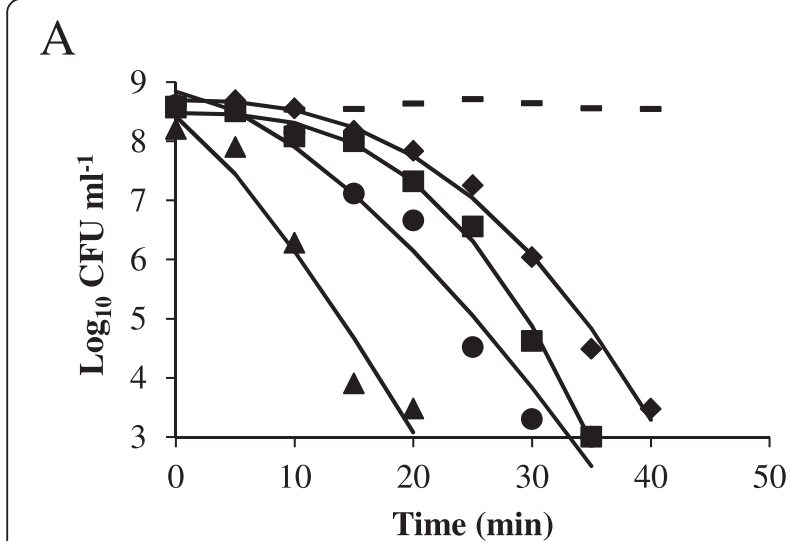

B

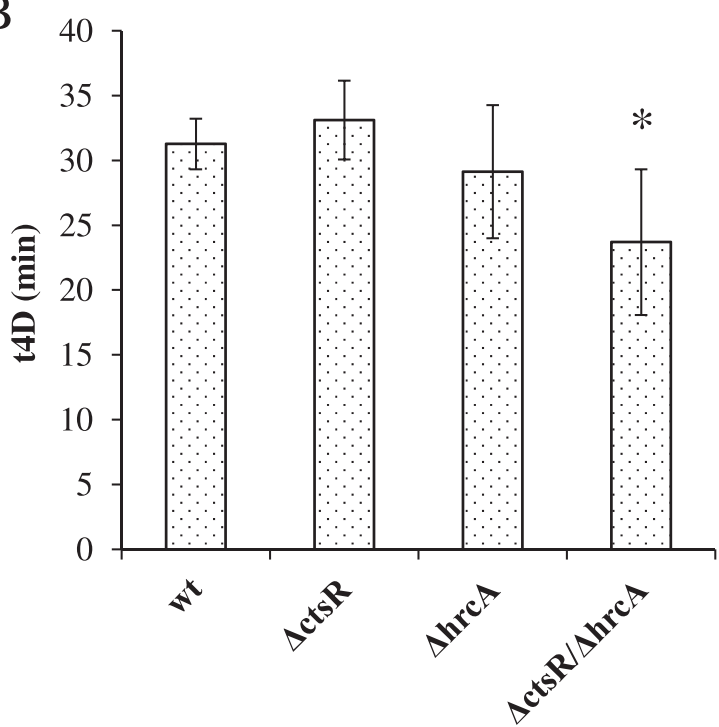

Figure 6 Involvement of CtsR and HrcA in hydrogen peroxide resistance. A) Colony forming units of $L$. plantarum WCFS1 (wt, squares), NZ3410 ( $\triangle c t s R$, diamonds), NZ3425 ${ }^{\mathrm{CM}}$ ( $\triangle$ hrcA, circles), and $\mathrm{NZZ3423}^{\mathrm{CM}}$ ( $\triangle c t s R \triangle h r c A$, triangles) cultures when subjected to $40 \mathrm{mM} \mathrm{H}_{2} \mathrm{O}_{2}$ exposure. As a control, the $\triangle c t s R \triangle h r c A$ strain was taken for incubation in PBS without $\mathrm{H}_{2} \mathrm{O}_{2}$ (dashes). Lines indicate the fitted reparameterized Weibull model data. Data shown are representative for 3 independent experiments. B) Time to the first $4 \log _{10}$ reductions $\left(t_{4 D}\right)$ for the same strains as in panel $A$. The $t_{4 D}$-value is the parameter estimate obtained by fitting a reparameterized Weibull model through the data and average for the 4 experiments. Error bars represent the 95\% confidence interval of the parameter estimate. Significant difference from the wt $(p<0.05)$ is indicated by *.

To understand the HrcA and CtsR mediated stress adaptation, transcriptome analyses were performed comparing the transcriptional profiles of the HrcA- and CtsR-deficient strains at $28^{\circ} \mathrm{C}$ and $40^{\circ} \mathrm{C}$. In addition, to unravel the intertwinement of the class I and class III stress response networks, a strain that lacked both repressors was included in this study. Transcriptome analyses of similar single mutants of either $h r c A$ or $c t s R$ have been reported for other species [4,62-66], and mutants lacking both repressors have been constructed in Listeria monocytogenes [62] and in Staphylococcus aureus [66]. Nevertheless, to the best of our knowledge, this study presents the first transcriptome analysis of a strain that is deficient for both regulators. Of the predicted $h r c A$ regulon members, no altered expression pattern was detected for the $\operatorname{rrp} E$, dnaK and $d n a J$ genes, which may be due to the involvement of additional regulatory factors in the control of expression of this chaperone genecluster. For example, it has been demonstrated that carbon catabolite control mediated through CcpA can affect the expression of the groELS and dnaK operons in L. plantarum, and that in a CcpA-deficient strain the expression of these functions could not be fully induced leading to reduced stress tolerance levels. Although these observations may not completely explain the lack of activation of $d n a K$ operon expression in the $h r c A$ mutant, they clearly imply that CcpA-activation could contribute to expression of the dnaK operon $[67,68]$. Moreover, in other organisms, e.g. in Streptococcus pneumonia, the transcription of the dnaK and groEL operons is regulated by the medium concentration of $\mathrm{Ca}^{2+}$ as well as by HrcA [69], suggesting that additional environmental factors may modulate $h r c A$ regulation of specific target genes and operons of its regulon. Although $l p \_0726$ is a predicted $h r c A$ regulon member, its transcription level was increased in the $\triangle c t s R$ and $\Delta c t s R \Delta h r c A:: c a t$ mutants. Besides transcriptional changes in the predicted regulons, $h r c A$ and $c t s R$ mutation led to a differential expression of genes involved in many functional classes during control and elevated temperature.

One of the deteriorating consequences encountered by cells growing at temperatures that can be considered as stress temperatures is denaturation and aggregation of proteins [70]. Lack of appropriate control of both the protein folding support (chaperones) and protein quality (Clp proteolysis) may elicit complementing gene expression responses involving genes belonging to different functional classes and affecting numerous cellular processes. These responses may include altered levels of regulator proteins in the cell, which may elicit changes in expression of a variety of regulons. Moreover, the levels of regulator protein may be differentially affected by the temperature of growth, leading to temperature-specific response of various regulatory networks, as was observed in this study. The drastic transcriptome changes elicited in the strain that lacks both CtsR and HrcA at control temperature is illustrative for the magnitude and complexity of the response required for the compensation for the deregulation of both class I and III stress responses. In addition, the results pinpoint that cell envelope remodeling plays an important role in the temperature adaptation in the wild-type strain, but is also prominently affected by the disruption of class I and III stress response networks. Intriguingly, it has been proposed that in prokaryotes heat shock responses 
are predominantly controlled by the membrane physical state [71-73], which is in agreement with the finding that adaptive responses include many membrane and envelope modulating functions. Moreover, HrcA has been proposed to be a membrane-associated protein in Helicobacter pylori, and even an integral membrane protein in Streptococcus pneumoniae. In addition, the hrcA-regulon member GroELS of Escherichia coli is involved in folding of both soluble and membrane-associated proteins, while concomitantly stabilizing lipid membranes $[49,74,75]$.

To understand the role of HrcA and CtsR in other stress conditions besides elevated temperature, the deregulation responses in the $h r c A$ and $c t s R$ mutant strains were compared with responses in the wild-type L. plantarum strain upon its exposure to specific stress conditions. The mutant lacking both $c t s R$ and $h r c A$ displayed significant decreased $\mathrm{H}_{2} \mathrm{O}_{2}$ tolerance levels compared with the wild type, suggesting that appropriate classI and III stressregulation are required for optimal peroxide stress adaptation in L. plantarum. Downregulation of genes encoding proteins involved in membrane lipid synthesis $(\operatorname{dak} 1 B$, dak2, dak3, and lp_1539) and cell wall (cps1 cluster) in this mutant possibly induce cell envelope modifications that weaken the cell when exposed to peroxide stress. Furthermore, class I and class III stress responses were previously reported to be involved in oxidative stress tolerance in Fusobacterium nucleatum, which was associated to induction of ClpB and DnaK in response to $\mathrm{H}_{2} \mathrm{O}_{2}$ stress [76]. A potentially more indirect link may exist between the Clp protease and $\mathrm{H}_{2} \mathrm{O}_{2}$ stress responses in $\mathrm{B}$. subtilis, where Clp protease activity is involved in regulation of Spx [21], which in its turn was shown to be induced upon $\mathrm{H}_{2} \mathrm{O}_{2}$ exposure [77].

Overall, deregulation of the CtsR and HrcA regulons in L. plantarum elicits compensatory responses that can be characterized by differential transcriptome analyses. These analyses reveal the modulation of several major functional classes, which appears to be temperature-dependent. Therefore, proper control of the CtsR and HrcA regulons are essential for maintaining optimal cell function in changing environments. Moreover, gene regulatory network reconstructions are essential to survey the full regulatory response of an organism. In these networks, the role of the canonical class I and III stress response regulators will be of great importance, because of their pleiotropic character.

\section{Additional files}

Additional file 1: Figure S1. Hybridization scheme for DNA microarrays using CDNA derived from L. plantarum WCFS1 (WT), NZ3410 ( $\Delta c t s R ; \mathrm{dC}$ ),

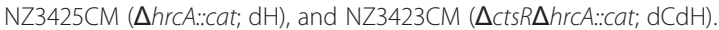

Temperature in $C^{\circ}$ is indicated after the slash. Duplicates were included (between brackets) and circled number indicates hybridization number. Tail and head of the arrow represent Cy3 and Cy5 labeling, respectively.
Additional file 2: Table S1. Differentially regulated genes in L. plantarum WCFS1 grown at $40^{\circ} \mathrm{C}$ compared to $28^{\circ} \mathrm{C}$.

Additional file 3: Table S2. Abbreviations used in Figure 4.

\section{Competing interests}

The authors declare that they have no competing interests.

\section{Authors' contributions}

$H v B-v d V, M W, P A B$, and MK designed the experiments, HvB-vdV and RB performed the experiments, $H v B-v d V, R B, M W, P A B$, and MK interpreted the data, and HvB-vdV,PAB, and MK drafted and revised the manuscript. All authors approved the version of the manuscript to be published.

\section{Acknowledgements}

The authors would like to acknowledge Heidy den Besten (Laboratory of Food Microbiology, Wageningen UR, The Netherlands) for her contribution to the Weibull model fitting.

\section{Author details}

${ }^{1}$ TI Food \& Nutrition, Nieuwe Kanaal 9A, 6709 PA Wageningen, The Netherlands. ${ }^{2} \mathrm{NIZO}$ food research, P.O. Box 20, 6710 BA Ede, The Netherland. ${ }^{3}$ Laboratory of Microbiology, Wageningen University and Research Centre, $\mathrm{P}$. O. Box 8033, 6700 EJ Wageningen, The Netherlands. ${ }^{4}$ Centre for Molecular and Biomolecular Informatics, Radboud University Medical Centre, P.O. Box 9101, 6500 HB Nijmegen, The Netherlands. ${ }^{5}$ Kluyver Centre for Genomics of Industrial Fermentation, P.O. Box 5057, 2600GA, Delft, The Netherlands. ${ }^{6}$ Host-Microbe Interactomics, Wageningen University and Research Centre, P. O. Box 338, 6700 AH Wageningen, The Netherlands. ${ }^{7}$ Present address: Food \& Biobased Research, Wageningen University and Research Centre, Bornse Weilanden 9, 6708 WG Wageningen, The Netherlands. ${ }^{8}$ Present address: Gut Biology and Microbiology, Danone Research, Bosrandweg 20, 6704 PH Wageningen, The Netherlands.

Received: 22 July 2013 Accepted: 11 November 2013 Published: 18 November 2013

\section{References}

1. Li H, Cao Y: Lactic acid bacterial cell factories for gamma-aminobutyric acid. Amino Acids 2010, 39(5):1107-1116.

2. Bourdichon F, Casaregola S, Farrokh C, Frisvad JC, Gerds ML, Hammes WP, Harnett J, Huys G, Laulund S, Ouwehand A, et al: Food fermentations: microorganisms with technological beneficial use. Int J Food Microbiol 2012, 154(3):87-97.

3. Ahrne S, Nobaek S, Jeppsson B, Adlerberth I, Wold AE, Molin G: The normal Lactobacillus flora of healthy human rectal and oral mucosa. J App/ Microbiol 1998, 85(1):88-94.

4. Lee NK, Yun CW, Kim SW, Chang HI, Kang CW, Paik HD: Screening of Lactobacilli derived from chicken feces and partial characterization of Lactobacillus acidophilus A12 as an animal probiotics. J Microbiol Biotechnol 2008, 18(2):338-342.

5. Siezen RJ, Tzeneva VA, Castioni A, Wels M, Phan HT, Rademaker JL, Starrenburg MJ, Kleerebezem M, Molenaar D, Van Hylckama Vlieg JE: Phenotypic and genomic diversity of Lactobacillus plantarum strains isolated from various environmental niches. Environ Microbiol 2010, 12(3):758-773.

6. FAO/WHO: Evaluation of Health and Nutritional Properties of Powder Milk with Live Lactic Acid Bacteria, Report of FAO/WHO expert consultation 1-4 October. ; 2001.

7. Lebeer S, Vanderleyden J, De Keersmaecker SC: Host interactions of probiotic bacterial surface molecules: comparison with commensals and pathogens. Nat Rev Microbiol 2010, 8(3):171-184.

8. Kleerebezem M, Hols P, Bernard E, Rolain T, Zhou M, Siezen RJ, Bron PA: The extracellular biology of the lactobacilli. FEMS Microbiol Rev 2010, 34(2):199-230.

9. Van de Guchte M, Serror P, Chervaux C, Smokvina T, Ehrlich SD, Maguin E: Stress responses in lactic acid bacteria. Antonie Van Leeuwenhoek 2002, 82(1-4):187-216.

10. De Angelis $M$, Gobbetti $M$ : Environmental stress responses in lactobacillus: a review. Proteomics 2004, 4(1):106-122. 
11. Spano G, Massa S: Environmental stress response in wine lactic acid bacteria: beyond bacillus subtilis. Crit Rev Microbiol 2006, 32(2):77-86.

12. Mills S, Stanton C, Fitzgerald G, Ross RP: Enhancing the stress responses of probiotics for a lifestyle from gut to product and back again. Microb Cell Fact 2011, 10(Suppl 1):15.

13. Schumann W: The Bacillus subtilis heat shock stimulon. Cell Stress Chaperones 2003, 8(3):207-217.

14. Darmon E, Noone D, Masson A, Bron S, Kuipers OP, Devine KM, van Dijl JM: A novel class of heat and secretion stress-responsive genes is controlled by the autoregulated CssRS two-component system of Bacillus subtilis. J Bacteriol 2002, 184(20):5661-5671.

15. Helmann JD, Wu MF, Kobel PA, Gamo FJ, Wilson M, Morshedi MM, Navre M, Paddon C: Global transcriptional response of Bacillus subtilis to heat shock. J Bacterio/ 2001, 183(24):7318-7328.

16. Narberhaus F: Negative regulation of bacterial heat shock genes. Mol Microbiol 1999, 31(1):1-8.

17. Corcoran BM, Stanton C, Fitzgerald G, Ross RP: Life under stress: the probiotic stress response and how it may be manipulated. Curr Pharm Des 2008, 14(14):1382-1399.

18. Van Bokhorst-van de Veen H, Bron PA, Wels M, Kleerebezem M, et al: Engineering robust lactic acid bacteria. In Stress Responses of Lactic Acid Bacteria. Edited by Tsakalidou E, Papadimitriou K. US: Springer; 2011:369-394.

19. Elsholz AK, Gerth U, Hecker M: Regulation of CtsR activity in low GC, Gram + bacteria. Adv Microb Physiol 2010, 57:119-144.

20. Derre I, Rapoport G, Msadek T: CtsR, a novel regulator of stress and heat shock response, controls $c l p$ and molecular chaperone gene expression in Gram-positive bacteria. Mol Microbiol 1999, 31(1):117-131.

21. Frees D, Savijoki $K$, Varmanen $P$, Ingmer $\mathrm{H}$ : Clp ATPases and ClpP proteolytic complexes regulate vital biological processes in low GC, Gram-positive bacteria. Mol Microbiol 2007, 63(5):1285-1295.

22. Chastanet A, Msadek T: ClpP of Streptococcus salivarius is a novel member of the dually regulated class of stress response genes in Gram-positive bacteria. J Bacteriol 2003, 185(2):683-687.

23. Marco ML, Pavan S, Kleerebezem M: Towards understanding molecular modes of probiotic action. Curr Opin Biotechnol 2006, 17(2):204-210.

24. Vesa T, Pochart P, Marteau P: Pharmacokinetics of Lactobacillus plantarum NCIMB 8826, Lactobacillus fermentum KLD, and Lactococcus lactis MG 1363 in the human gastrointestinal tract. Aliment Pharmacol Ther 2000 14(6):823-828.

25. Van Bokhorst-van de Veen H, van Swam I, Wels M, Bron PA, Kleerebezem M: Congruent strain specific intestinal persistence of Lactobacillus plantarum in an intestine-mimicking in vitro system and in human volunteers. PLOS ONE 2012, 7(9):44588

26. Kleerebezem M, Boekhorst J, van Kranenburg R, Molenaar D, Kuipers OP, Leer R, Tarchini R, Peters SA, Sandbrink HM, Fiers MW, et al: Complete genome sequence of Lactobacillus plantarum WCFS1. Proc Natl Acad Sci USA 2003, 100(4):1990-1995.

27. Teusink B, Van Enckevort FH, Francke C, Wiersma A, Wegkamp A, Smid EJ, Siezen RJ: In silico reconstruction of the metabolic pathways of Lactobacillus plantarum: comparing predictions of nutrient requirements with those from growth experiments. Appl Environ Microbiol 2005, 71(11):7253-7262.

28. Teusink B, Wiersma A, Molenaar D, Francke C, de Vos WM, Siezen RJ, Smid EJ: Analysis of growth of Lactobacillus plantarum WCFS1 on a complex medium using a genome-scale metabolic model. J Biol Chem 2006, 281(52):40041-40048.

29. Lambert JM, Bongers RS, Kleerebezem M: Cre-lox-based system for multiple gene deletions and selectable-marker removal in Lactobacillus plantarum. Appl Environ Microbiol 2007, 73(4):1126-1135.

30. Fiocco D, Collins M, Muscariello L, Hols P, Kleerebezem M, Msadek T, Spano G: The Lactobacillus plantarum $\mathrm{fts} H$ gene is a novel member of the CtsR stress response regulon. J Bacteriol 2009, 191(5):1688-1694.

31. Fiocco D, Capozzi V, Collins M, Gallone A, Hols P, Guzzo J, Weidmann S, Rieu A, Msadek T, Spano G: Characterization of the CtsR stress response regulon in Lactobacillus plantarum. J Bacteriol 2010, 192(3):896-900.

32. Wels M, Francke C, Kerkhoven R, Kleerebezem M, Siezen RJ: Predicting cis-acting elements of Lactobacillus plantarum by comparative genomics with different taxonomic subgroups. Nucleic Acids Res 2006, 34(7):1947-1958.

33. Wels M, Overmars L, Francke C, Kleerebezem M, Siezen RJ: Reconstruction of the regulatory network of Lactobacillus plantarum WCFS1 on basis of correlated gene expression and conserved regulatory motifs. Microb Biotechnol 2011, 4(3):333-344.

34. Pieterse B, Leer RJ, Schuren FH, Van der Werf MJ: Unravelling the multiple effects of lactic acid stress on Lactobacillus plantarum by transcription profiling. Microbiology 2005, 151(Pt 12):3881-3894

35. Serrano LM, Molenaar D, Wels M, Teusink B, Bron PA, De Vos WM, Smid EJ: Thioredoxin reductase is a key factor in the oxidative stress response of Lactobacillus plantarum WCFS1. Microb Cell Fact 2007, 6(1):29.

36. Stevens MJA: Transcriptiome Response of Lactobacillus Plantarum to Global Regulator Deficiency, Stress and other Environmental Conditions. Wageningen: Thesis Wageningen University; 2008

37. Fiocco D, Capozzi V, Goffin P, Hols P, Spano G: Improved adaptation to heat, cold, and solvent tolerance in Lactobacillus plantarum. Appl Microbio Biotechnol 2007, 77(4):6.

38. Van Bokhorst-van De Veen H, Abee T, Tempelaars M, Bron PA, Kleerebezem M, Marco ML: Short- and long-term adaptation to ethanol stress and its cross-protective consequences in Lactobacillus plantarum. Appl Environ Microbio 2011, 77(15):5247-5256

39. Bron PA, Meijer M, Bongers RS, De Vos WM, Kleerebezem M: Dynamics of competitive population abundance of Lactobacillus plantarum ivi gene mutants in faecal samples after passage through the gastrointestinal tract of mice. J Appl Microbiol 2007, 103(5):1424-1434.

40. Van Bokhorst-van De Veen $H$, Lee IC, Marco ML, Wels M, Bron PA, Kleerebezem M: Modulation of Lactobacillus plantarum gastrointestinal robustness by fermentation conditions enables identification of bacterial robustness markers. PLOS ONE 2012, 7(7):e39053.

41. Meijerink M, van Hemert S, Taverne N, Wels M, de Vos P, Bron PA, Savelkoul HF, van Bilsen J, Kleerebezem M, Wells JM: Identification of genetic loci in Lactobacillus plantarum that modulate the immune response of dendritic cells using comparative genome hybridization. PLOS ONE 2010, 5(5):e10632.

42. Marco ML, Peters TH, Bongers RS, Molenaar D, Van Hemert S, Sonnenburg $J$, Gordon Il, Kleerebezem M: Lifestyle of Lactobacillus plantarum in the mouse caecum. Environ Microbiol 2009, 11(10):2747-2757.

43. Yang YH, Dudoit S, Luu P, Lin DM, Peng V, Ngai J, Speed TP: Normalization for CDNA microarray data: a robust composite method addressing single and multiple slide systematic variation. Nucleic Acids Res 2002, 30(4):e15.

44. Kuipers OP, Kok J, Trelles O, Garcia de la Nava J, Van Hijum SA: MicroPreP: a cDNA microarray data pre-processing framework. Appl Bioinformatics 2003, 2(4):241-244.

45. Baldi $P$, Long AD: A Bayesian framework for the analysis of microarray expression data: regularized $t$-test and statistical inferences of gene changes. Bioinformatics 2001, 17(6):509-519.

46. Shannon P, Markiel A, Ozier O, Baliga NS, Wang JT, Ramage D, Amin N, Schwikowski B, Ideker T: Cytoscape: a software environment for integrated models of biomolecular interaction networks. Genome Res 2003, 13(11):2498-2504.

47. Maere S, Heymans K, Kuiper M: BiNGO: a Cytoscape plugin to assess overrepresentation of gene ontology categories in biological networks. Bioinformatics 2005, 21(16):3448-3449.

48. Bailey TL, Boden M, Buske FA, Frith M, Grant CE, Clementi L, Ren J, Li WW, Noble WS: MEME SUITE: tools for motif discovery and searching. Nucleic Acids Res 2009, 37(Web Server issue):202-208.

49. Torok Z, Horvath I, Goloubinoff P, Kovacs E, Glatz A, Balogh G, Vigh L: Evidence for a lipochaperonin: association of active protein-folding GroESL oligomers with lipids can stabilize membranes under heat shock conditions. Proc Natl Acad Sci USA 1997, 94(6):2192-2197.

50. Bron PA, Marco M, Hoffer SM, Van Mullekom E, De Vos WM, Kleerebezem M: Genetic characterization of the bile salt response in Lactobacillus plantarum and analysis of responsive promoters in vitro and in situ in the gastrointestinal tract. J Bacterio/ 2004, 186(23):7829-7835.

51. Metselaar Kl, Den Besten HM, Abee T, Moezelaar R, Zwietering MH: Isolation and quantification of highly acid resistant variants of Listeria monocytogenes. Int J Food Microbiol 2013, 166(3):508-514.

52. Bron PA, Grangette C, Mercenier A, De Vos WM, Kleerebezem M: Identification of Lactobacillus plantarum genes that are induced in the gastrointestinal tract of mice. J Bacterio/ 2004, 186(17):5721-5729.

53. Bron PA, Molenaar D, De Vos WM, Kleerebezem M: DNA micro-array-based identification of bile-responsive genes in Lactobacillus plantarum. J Appl Microbiol 2006, 100(4):728-738

54. Stevens MJ, Molenaar D, De Jong A, De Vos WM, Kleerebezem M: Involvement of the mannose phosphotransferase system of Lactobacillus 
plantarum WCFS1 in peroxide stress tolerance. Appl Environ Microbiol 2010, 76(11):3748-3752.

55. Russo P, De la Luz MM, Capozzi V, De Palencia PF, Lopez P, Spano G, Fiocco D: Comparative proteomic analysis of Lactobacillus plantarum WCFS1 and deltacts $R$ mutant strains under physiological and heat stress conditions. Int J Mol Sci 2012, 13(9):10680-10696.

56. Hufner E, Markieton T, Chaillou S, Crutz-Le Coq AM, Zagorec M, Hertel C: Identification of Lactobacillus sakei genes induced during meat fermentation and their role in survival and growth. App/ Environ Microbiol 2007, 73(8):2522-2531.

57. Nair S, Derre I, Msadek T, Gaillot O, Berche P: CtsR controls class III heat shock gene expression in the human pathogen Listeria monocytogenes. Mol Microbiol 2000, 35(4):800-811.

58. Karatzas KA, Bennik MH: Characterization of a Listeria monocytogenes Scott A isolate with high tolerance towards high hydrostatic pressure. Appl Environ Microbiol 2002, 68(7):3183-3189.

59. Zotta T, Asterinou K, Rossano R, Ricciardi A, Varcamonti M, Parente E: Effect of inactivation of stress response regulators on the growth and survival of Streptococcus thermophilus Sfi39. Int J Food Microbiol 2009, 129(3):211-220.

60. Schulz A, Schumann W: hrcA, the first gene of the Bacillus subtilis dnaK operon encodes a negative regulator of class I heat shock genes. J Bacteriol 1996, 178(4):1088-1093.

61. Hu Y, Oliver HF, Raengpradub S, Palmer ME, Orsi RH, Wiedmann M, Boor KJ: Transcriptomic and phenotypic analyses suggest a network between the transcriptional regulators HrcA and sigmaB in Listeria monocytogenes. Appl Environ Microbiol 2007, 73(24):7981-7991.

62. Elsholz AK, Hempel K, Pother DC, Becher D, Hecker M, Gerth U: CtsR inactivation during thiol-specific stress in low GC, Gram + bacteria. Mol Microbiol 2011, 79(3):772-785

63. Van Baarlen P, Troost F, van der Meer C, Hooiveld G, Boekschoten M, Brummer RJ, Kleerebezem M: Human mucosal in vivo transcriptome responses to three lactobacilli indicate how probiotics may modulate human cellular pathways. Proc Natl Acad Sci USA 2011, 108(Suppl 1):4562-4569.

64. Hummelen R, Vos AP, Van't Land B, Van Norren K, Reid G: Altered host-microbe interaction in HIV: a target for intervention with pro- and prebiotics. Int Rev Immunol 2010, 29(5):485-513.

65. Roncarati D, Danielli A, Spohn G, Delany I, Scarlato V: Transcriptional regulation of stress response and motility functions in Helicobacter pylori is mediated by HspR and HrcA. J Bacteriol 2007, 189(20):7234-7243.

66. Chastanet A, Fert J, Msadek T: Comparative genomics reveal novel heat shock regulatory mechanisms in Staphylococcus aureus and other Gram-positive bacteria. Mol Microbiol 2003, 47(4):1061-1073.

67. Castaldo C, Siciliano RA, Muscariello L, Marasco R, Sacco M: CcpA affects expression of the groESL and dnaK operons in Lactobacillus plantarum. Microb Cell Fact 2006, 5:35.

68. Mazzeo MF, Cacace G, Peluso A, Zotta T, Muscariello L, Vastano V, Parente E, Siciliano RA: Effect of inactivation of $c с p A$ and aerobic growth in lactobacillus plantarum: a proteomic perspective. J Proteomics 2012, 75(13):4050-4061.

69. Kim SN, Bae YG, Rhee DK: Dual regulation of dnaK and groE operons by HrcA and Ca++ in Streptococcus pneumoniae. Arch Pharm Res 2008, 31(4):462-467.

70. Somero GN: Proteins and temperature. Annu Rev Physiol 1995, 57:43-68

71. Porta A, Torok Z, Horvath I, Franceschelli S, Vigh L, Maresca B: Genetic modification of the Salmonella membrane physical state alters the pattern of heat shock response. J Bacteriol 2010, 192(7):1988-1998.

72. Porta A, Eletto A, Torok Z, Franceschelli S, Glatz A, Vigh L, Maresca B: Changes in membrane fluid state and heat shock response cause attenuation of virulence. J Bacterio/ 2010, 192(7):1999-2005.

73. Coucheney F, Gal L, Beney L, Lherminier J, Gervais P, Guzzo J: A small HSP, Lo18, interacts with the cell membrane and modulates lipid physical state under heat shock conditions in a lactic acid bacterium. Biochim Biophys Acta 2005, 1720(1-2):92-98.

74. Kwon HY, Kim EH, Tran TD, Pyo SN, Rhee DK: Reduction-sensitive and cysteine residue-mediated Streptococcus pneumoniae HrcA oligomerization in vitro. Mol Cells 2009, 27(2):149-157.

75. Roncarati D, Spohn G, Tango N, Danielli A, Delany I, Scarlato V: Expression, purification and characterization of the membrane-associated HrcA repressor protein of Helicobacter pylori. Protein Expr Purif 2007, 51(2):267-275
76. Steeves CH, Potrykus J, Barnett DA, Bearne SL: Oxidative stress response in the opportunistic oral pathogen Fusobacterium nucleatum. Proteomics 2011, 11(10):2027-2037.

77. Tam LT, Antelmann H, Eymann C, Albrecht D, Bernhardt J, Hecker M: Proteome signatures for stress and starvation in Bacillus subtilis as revealed by a 2-D gel image color coding approach. Proteomics 2006, 6(16):4565-4585

doi:10.1186/1475-2859-12-112

Cite this article as: Van Bokhorst-van de Veen et al:: Transcriptome signatures of class I and III stress response deregulation in Lactobacillus plantarum reveal pleiotropic adaptation. Microbial Cell Factories 2013 12:112.

\section{Submit your next manuscript to BioMed Central and take full advantage of:}

- Convenient online submission

- Thorough peer review

- No space constraints or color figure charges

- Immediate publication on acceptance

- Inclusion in PubMed, CAS, Scopus and Google Scholar

- Research which is freely available for redistribution 